\title{
SATS Awards 2016
}

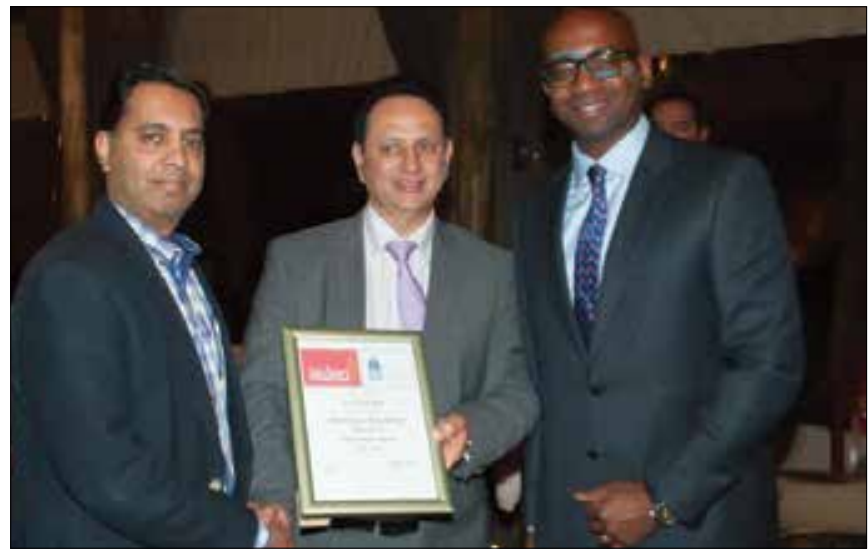

AstraZeneca Respiratory Research Fellowship Award 2015, awarded to Dr Ali Esmail (UCT). Accepting the award is Prof. Dheda (UCT). With South African Thoracic Society President Prof. U Lalloo and AstraZeneca representative Rodney Gillespie.

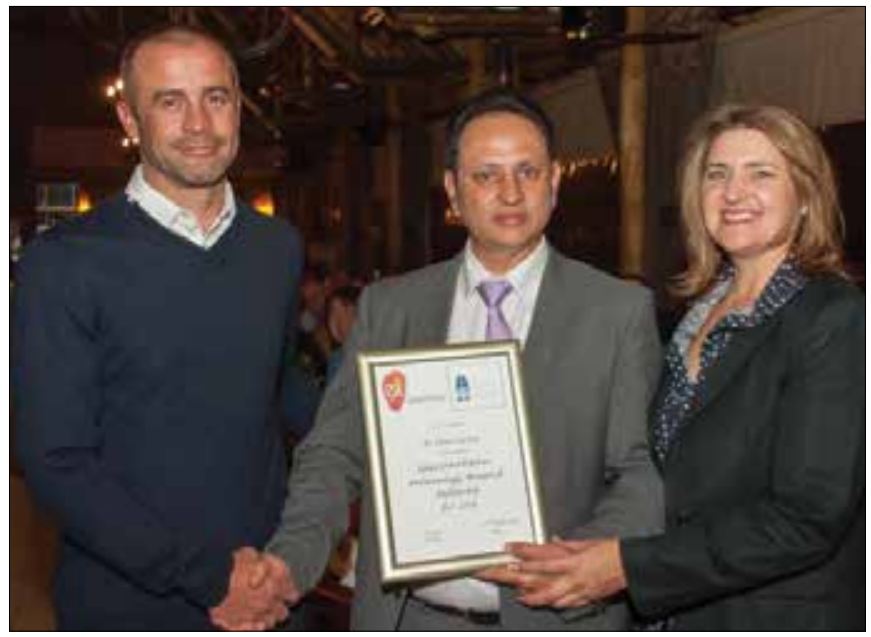

Glaxo-Smith-Kline Pulmonology Research Fellowship 2015, awarded to Dr Charl Verwey (Wits). With SATS President Prof. U Lalloo and GSK representative Ms A Beyl.

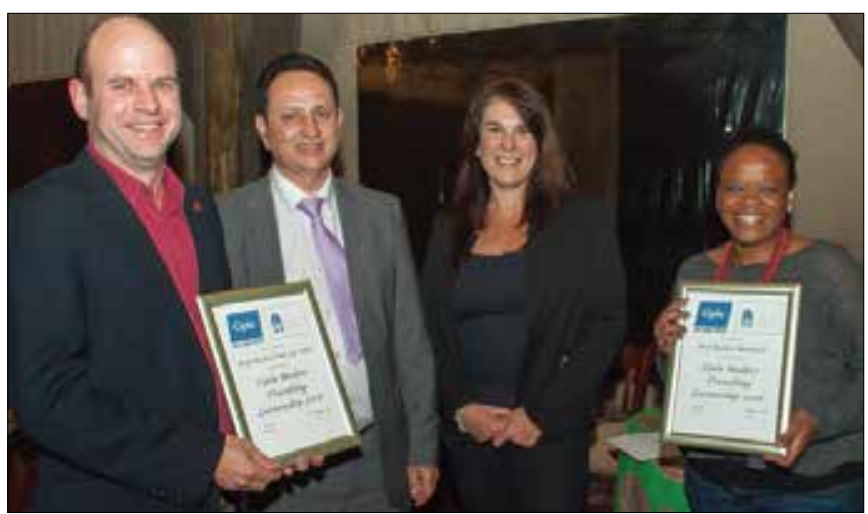

Cipla-Medpro Travelling Lectureship 2016, awarded to Prof. Refiloe Masekela (UKZN) and Prof. Richard van Zyl-Smit (UCT). With SATS President Prof. U Lalloo and Cipla representative Ms Lisl De Villiers.

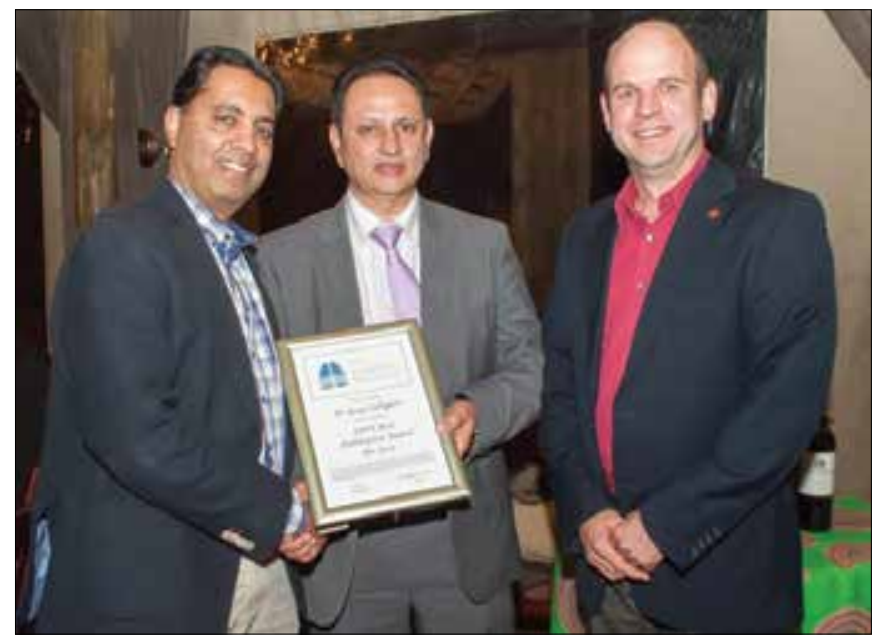

SATS Best Publication Award 2016, awarded to Dr G Calligaro (UCT). Accepting the award is Prof. Dheda (UCT). With SATS President Prof. $U$ Lalloo, and Chairperson of the SATS Scholarship Selection Committee Prof. R van Zyl-Smit.

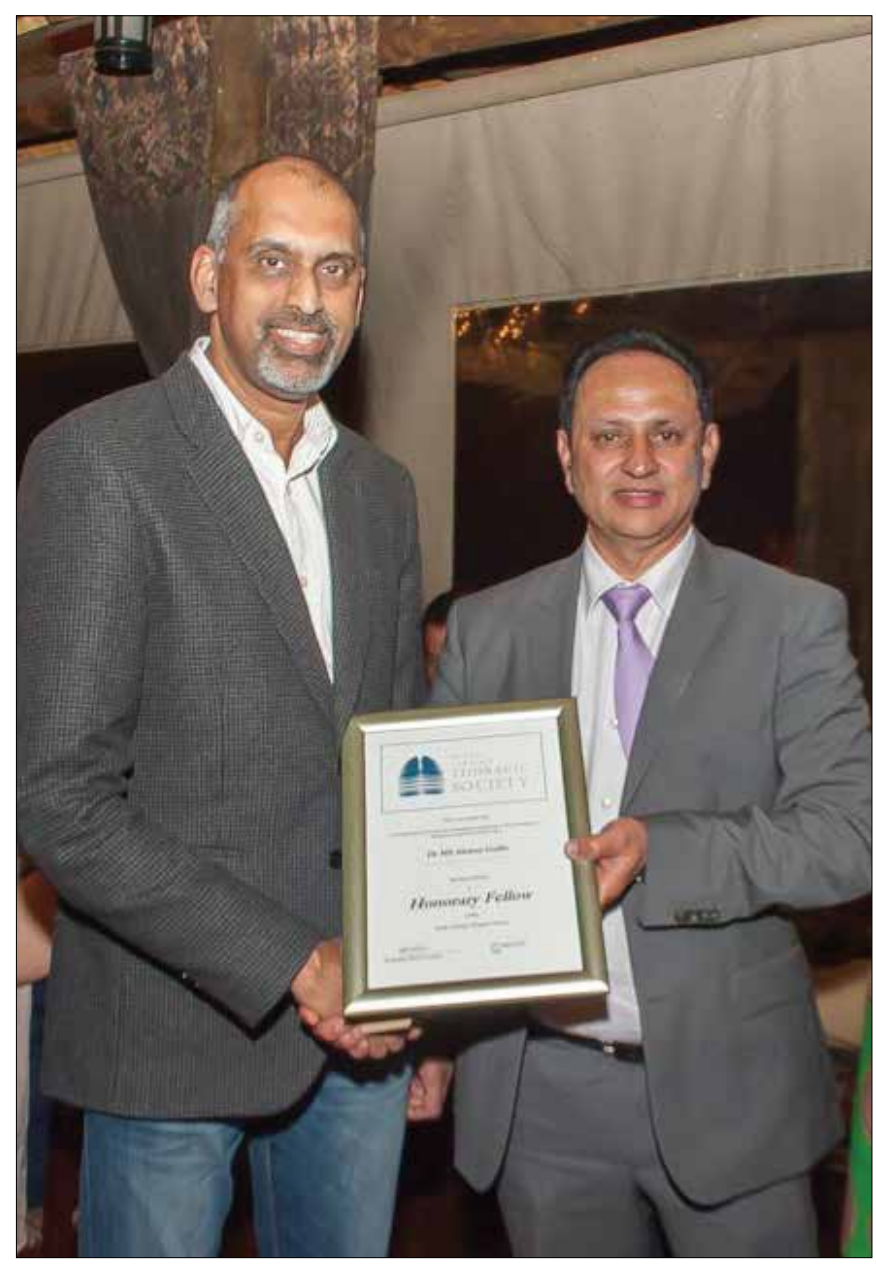

SATS Honorary Award for 2016, awarded to Dr MS Abdool Gaffar (KZN). With SATS President Prof. U Lalloo. 